\title{
MULTIMEDIA PRESENTATIONS AND TEACHING ABOUT THE WORLD AROUND US, MAN AND NATURE, AND MAN AND SOCIETY IN GRADES 1 - 4
} Vanya Ivanova ${ }^{1}$

\begin{abstract}
The article aims to justify and elucidate the role of multimedia presentations in learning about the world around us. Multimedia presentations accompany early training aimed at the child's natural and social environment. They are systematically used due to the visual nature of the predominant learning material, which quite often combines illustrative and educational functions.

This article focuses on the didactic use of presentations in lessons and its methodology. The objective of this research is to establish which didactic tasks are performed with the help of multimedia presentations in lessons.

The results in the areas studied show that there is no single unified method for using multimedia presentations in the lessons on the surrounding world. In practice, different approaches are used, which, in some cases, are incompatible with the traditional teaching procedure.
\end{abstract}

UDC Classification: 37.01., DOI: https://doi.org/10.12955/pss.v2.216

Key words: multimedia presentation, training for the surrounding world, methodology of the training for the surrounding world.

\section{Introduction}

Multimedia presentations are increasingly becoming a crucial element of instruction related to the natural and social environment in primary school. Most of the teaching material requires visualization and presentations provide that with the help of their illustrative functions. The term 'presentation' itself comes from the English word 'present'.

In computer science, presentations are a means of arranging and presenting information to an audience. They combine text with various multimedia tools such as digital images, sounds, videos, etc., which contribute to attracting and retaining the attention of its perceiver as it engages not only the sense of hearing but also vision. For educational purposes, presentations are usually created with the PowerPoint program under Microsoft Office. The PPTs contain separate slides over which the desired information is sequentially arranged along with selected designs and the necessary tools and objects such as titles, subheadings, bullets, images, tables, diagrams, etc.

A study on the practical application of multimedia presentations in teaching about the world around us, man and nature, and man and society show that MMP is often used as a modern electronic version of lesson planning. The presentations often contain chronologically arranged educational content combining text and images for illustrative purposes. We can also find various questions and exercises ordered systematically in the lesson like updating knowledge and skills, getting acquainted with objects and phenomena, completing tasks aimed at controlling and assessing students' knowledge, etc. This way, the presentation with the preliminary arrangement of the slides becomes central to both the teacher and the students. Generally, explanations in the lesson are presented in the form of text on the slides. It is then read by the teacher or student without the required accents, feedback and insight that accompany the traditional presentation of the teacher. Should teaching be equated with presentation? We hope that this study will answer such questions.

In practice, ready-made presentations are frequently used, created, and published on the Internet by teachers. There are also cases of adaptations. Here the question arises: Are the pedagogic and methodological functions of the presentation considered as a specific didactic tool?

Many times content from the textbook is directly copied onto a slide, as a result of which students' concentrate more on the text rather than the comprehension of the topic. This makes the text pivotal to the training.

Usually, the presentation manages to attract and retain the interest of students. If it fits into the structure of the lesson and is not used mechanically, the results are positive. However, if the lesson is to follow the prepared presentation, then the presentation becomes the main focus and does not harmonize with the reality of learning. There are some requirements established in the practice of training for the topics of the world around us, man and nature, and man and society.

\footnotetext{
${ }^{1}$ Trakia University, Faculty of Education, Stara Zagora, Bulgaria, vanja_p@abv.bg
} 
- For students in primary school, the presentation should not be overloaded with lots of information, but should only perform specific functions in the lesson - to illustrate, to help get acquainted with the terms and objects, to assign tasks for independent work, etc.

- The number of slides needs to be specified according to the goals. In grades 1-2 we should not have more than 12 slides, and in grades $3-4$, up to 15 slides.

- Do not overload the slide with objects, especially of the same kind.

- Show objects in a large enough font in order to be able to view both the object as a whole and its parts - major and minor.

- The different parts of the object must be easily distinguishable. This can be done by employing different colors and sizes.

- The object should be displayed in its natural environment without anthropomorphic elements like a bunny with a hat, a sheep with ribbons, etc.

- To aid in the comparison and establishment of the common and essential features of a class of objects different diagrams can be used. For example, when examining bushes, show a wellbranched stem with pictures and explanations of different types of bushes.

- There can also be a set of tasks for self-implementation, solving problems and issues and learning how to act in different situations.

\section{Literature Review}

The problem under consideration is posed by B. Ronsivalle and M. Orlando (2011): "In the last years teachers' competences in reinterpreting contents and designing slides haven't improved. Often, presentations repeat what the teacher says. Students attend lessons with 'wall of text' slides trying to read them while the instructor is speaking. Instead of facilitating the learning process, presentations become a distraction".

According to Peycheva (2018), "the multimedia didactic materials in the lesson to a higher degree provide the necessary clarity and accessibility of the presented information, and this reflects on the productivity in the work of the students. In the conditions of presentation, combined with a short story or explanation, the principle of multisensory is present, in which a complete impact on the senses of the students is realized. This leads to a fuller, more accurate perception and awareness of new knowledge..."

B. Damyanov (2014) says, "depending on the didactic purpose the presentation can be: informative presentation, presentation-task, problem presentation, and according to the way of presenting the material - complete and fragmentary. The overall presentation shows a series of slides in which a topic is developed at a certain level ... The presentation fragment is a system of slides that do not logically exhaust the topic." In primary school education, this type of presentation is the most appropriate. They can be used to activate students' cognitive activity or for other purposes. They can only contain images, short text images, and questions and tasks".

This author draws attention to a number of technical requirements and features in the creation of presentations that are not the subject of this study.

I. Petrova and M. Petrova (2007) do a research on the educational-cognitive activity of the students while learning about "human and nature" by way of multimedia presentations. With the highly developed information and communication technologies (ICT) of today and particularly with the multimedia presentations, the motivation to study natural processes and phenomena develops for students.

D. McDonald (2004) points out that "the characteristics of MMS, such as interactivity, consistency, and availability can provide a demonstrable improvement over traditional training methods".

D. Kirilova (2019) examines the role of multimedia presentations in environmental education: "Multimedia presentations are appropriate didactic tools for implementing an environmental approach in the process of technological learning, especially in the first grade, as they contain mainly visualized information that is more easily perceived by students at this stage of their development. The visualization of plant and animal objects, combined with the relevant terms, contributes to a more successful and accurate perception of the information."

In the "characteristics of the objects in educational resources from the [viewpoint] of their pedagogical projections" developed by M. Trifonova (2018 - 1), multimedia presentation in training is considered as a set of digital objects that function as educational objects. 
On the other hand, M. Trifonova (2018 - 2) defines them as didactic objects that are closely related to digital competences: "The convergence of different areas of knowledge with information technology forms a border area in which there are needs for hybrid competencies to solve of emerging tasks and it is not enough to focus only on the nature and functionality of technology. A digital adaptation of the individual components of any other field of knowledge is needed in order to be able to transform, enrich and transfer them."

S. Lazarova (2016) discusses the typical mistakes of students in the preparation and use of presentations in training of environmental studies, man and nature, and man and society: "Multimedia presentations are increasingly used in modern education. These mandate students to master the specific educational content through the inclusion of a greater portion of their senses, which is a prerequisite for continued remembering. In their creation and usage, there are mistakes that negatively affect the quality of the lesson. They can be avoided or minimized if students know the requirements in preparing the presentation and what are the most common mistakes, to comply with them and to try to avoid them".

On reviewing the pedagogical publications on the given topics, we find that the motivation and development aspect of multimedia presentations are considered more often. The specific methodological tasks they solve are left out in most researches.

\section{Methodology}

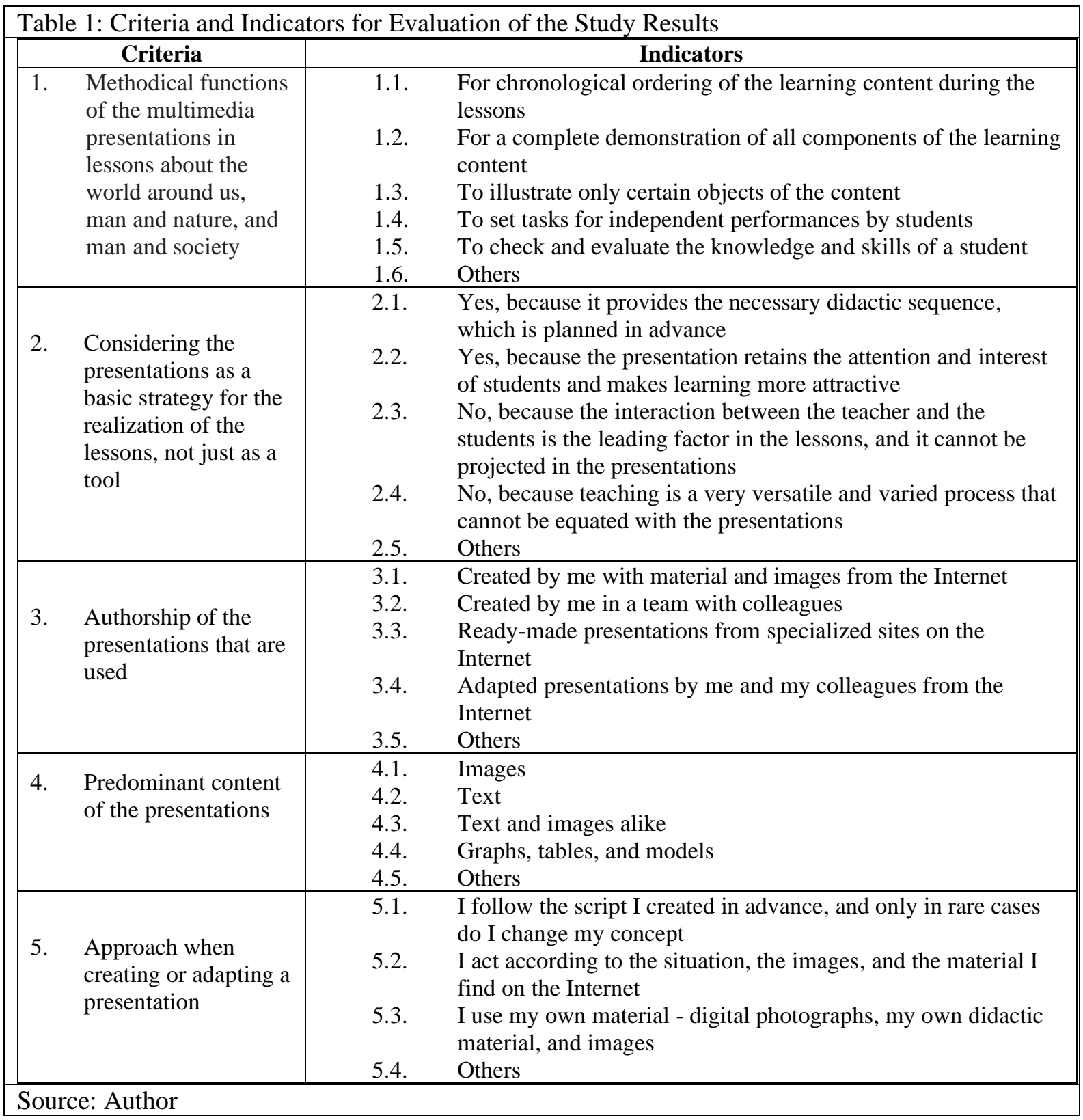


On the basis of the above-developed set of criteria and indicators, a survey was prepared and conducted among 34 active primary school teachers from the city of Stara Zagora. There was one noteworthy answer - the position that dominates the work of a colleague. The survey was, however, anonymous. There is another possible view that surfaced during the survey - "Others".

\begin{tabular}{|c|c|}
\hline Indicators & $\%$ \\
\hline 1.1. For chronological ordering of the learning content during the lessons & $12 \%$ \\
\hline 1.2. For a complete demonstration of all components of the learning content & $20 \%$ \\
\hline 1.3. To illustrate only certain objects of the content & $41 \%$ \\
\hline 1.4. To set tasks for independent performances by students & $12 \%$ \\
\hline 1.5. To check and evaluate the knowledge and skills of a student & $12 \%$ \\
\hline 1.6. Others & $3 \%$ \\
\hline
\end{tabular}

The results obtained from the survey based on Criterion 1 (Table 2) show that teachers have a good theoretical orientation in the various didactic and methodological functions that presentations offer. $41 \%$ teachers indicated that the most common function of presentations is an illustration, whereas only four teachers suggested that they arranged the learning content in the lesson chronologically with the help of presentations.

It is a rather impressive justification and understanding of the role of multimedia presentations and the limits on their effectiveness. In the "Others" option, one of the respondents claimed: "Multimedia presentation provides very rich opportunities for illustration, animation, diversification, attractive interpretation of educational content in $\mathrm{OS}, \mathrm{PE}, \mathrm{CHO}$, but only if it is created and used wisely for the specific objectives of the lesson. It can be very harmful if the teacher uses it and assigns a leading role [to it] in the lesson. A presentation can be a means to an end for a teacher, but it cannot be a teacher".

Table 3: Results by Criterion 2: Considering the Presentations as a Basic Strategy for the Realization of the Lessons, not Just as a Tool.

\begin{tabular}{|l|c|}
\multicolumn{1}{|c|}{ Indicators } & \% \\
\hline 2.1. Yes, because it provides the necessary didactic sequence, which is planned in advance & $15 \%$ \\
\hline $\begin{array}{l}\text { 2.2. Yes, because the presentations retain the attention and interest of students and make } \\
\text { learning more attractive }\end{array}$ & $6 \%$ \\
\hline $\begin{array}{l}2.3 \text {. No, because the interaction between the teacher and the students is the leading factor } \\
\text { in the lessons, and it cannot be projected in the presentations }\end{array}$ & $29 \%$ \\
\hline $\begin{array}{l}\text { 2.4. No, because teaching is a very versatile and varied process that cannot be equated } \\
\text { with the presentations }\end{array}$ & $50 \%$ \\
\hline 2.5. Others & $0 \%$ \\
\hline Source: Author & \\
\hline
\end{tabular}

According to Criterion 2 (Table 3), the results show that a small percentage of teachers accept presentations as a leading factor in determining the structure and course of the lessons. This is due to the fact that presentations provide interactive learning and account for variability. However, one of the respondents came to a conclusion that "Presentation is not teaching". This allows us to make the assumption that presentations are not given a major role in the course of the lesson, and they do not guide the methodological decisions of the teacher.

\begin{tabular}{|l|c|}
\hline \multicolumn{1}{|c|}{ Table 4: Results by Criterion 3: Authorship of the Presentations that are Used } \\
\hline \multicolumn{1}{|c|}{ Indicators } & $\%$ \\
\hline 3.1. Created by me with material and images from the Internet & $47 \%$ \\
\hline 3.2. Created by me in a team with colleagues & $15 \%$ \\
\hline 3.3. Ready-made presentations from specialized sites on the Internet & $9 \%$ \\
\hline 3.4. Adapted presentations by me and my colleagues from the Internet & $26 \%$ \\
\hline 3.5. Others & $3 \%$ \\
\hline Source: Author & \\
\hline
\end{tabular}

As per Criterion 3 (Table 4), most teachers create their own presentations with material from the Internet. It is important to note that in this survey, some of the teachers responded by saying that they used ready- 
made presentations from specialized sites and groups. This is an argument in context of subordinating the presentation to the lesson, not to teacher preparations.

\begin{tabular}{|l|c|}
\hline \multicolumn{1}{|c|}{ Table 5: Results by Criterion 4: Predominant Content of the Presentations } \\
\hline \multicolumn{1}{|c|}{ Indicators } & \% \\
\hline 4.1. Images & $62 \%$ \\
\hline 4.2. Text & $0 \%$ \\
\hline 4.3. Text and images alike & $26 \%$ \\
\hline 4.4. Graphs, tables and models & $9 \%$ \\
\hline 4.5. Others & $3 \%$ \\
\hline Source: Author & \\
\hline
\end{tabular}

The outcomes of Criterion 4 (Table 5) show that a majority of teachers create presentations due to their illustrative functions. No teacher points out the fact that the text dominates the presentations. This confirms the conclusion that primary school teachers take into account the different applications of presentations and use them according to the age characteristics of the students.

\begin{tabular}{|l|c|}
\hline \multicolumn{1}{|c|}{ Table 6: Results by Criterion 5: Approach When Creating or Adapting a Presentation } \\
\hline \multicolumn{1}{|c|}{ Indicators } & $\%$ \\
\hline 5.1. I follow the script I created in advance, and only in rare cases do I change my concept & $64 \%$ \\
\hline 5.2. I act according to the situation, the images, and the material I find on the Internet & $15 \%$ \\
\hline 5.3. I use my own material - digital photographs, my own didactic material and images & $18 \%$ \\
\hline 5.4. Others & $3 \%$ \\
\hline Source: Author
\end{tabular}

The results of Criterion 5 (Table 6) show that the necessary didactic consistency and meaningfulness in creating presentations is always present. $64 \%$ of the surveyed teachers follow their predetermined schedule. A significantly smaller percentage acts situationally and is influenced by the material they find on the Internet. This is evidence of the technical focus and significance of presentations.

\section{Conclusion}

The outcomes show that there are no explicit methodological requirements for the use of the multimedia presentations in lessons on "the world around us", "man and nature" and "man and society".

Presentations do not restrict themselves to performing the same functions for different types of lessons. Depending on the type and objectives of the lesson, the presentation has different technical functions. In lessons for new knowledge, they mainly illustrate and bring out the most vital and novel concepts, rules, etc. When it's a lesson with experimental or research work, a presentation aids in demonstrating the whole experiment or given algorithm, or the sequence of actions. Summary lessons present practical tasks as well as activities for testing and self-checking knowledge. Here, presentations contain the test questions and tasks which can be displayed on screen for a certain time, and the students can simultaneously write down the answers on a piece of paper, which is later on evaluated. This allows the students to contemporarily perform tasks when there is a time limit and a need for speedy work. Besides, it also gives a very good opportunity for self-examination. After the student has recorded his/her answer, the correct option is displayed and the student has the opportunity to correct a mistake and to consolidate the knowledge at the same time.

The presentations in lessons do not hold center stage. They only support the goals of the lesson. The preparation of the presentation itself commences with identifying its functions in the lesson. In this regard, it is important to judge what the learning content aims to demonstrate in the presentation. Undoubtedly, uploading texts or illustrations from the textbook is a controversial decision. It is owing to the expectations we have from the tasks that must be accomplished by the presentation that we start creating a "script" for it. The presentation's main focus should be to disseminate essential information related to the topics and to help understand different concepts, while also not distracting attention. Basic information can be presented through entertaining slides.

The conducted research shows that, declaratively, the teachers are correctly oriented in the mentioned didactic functions of multimedia presentation.

\section{References}

Damyanov, B. (2014) Multimedia in the Teaching of Fine Arts. In: Perspectives in Education. Paisii Hilendarski University Publishing House, Plovdiv, pp. 23-33. 
Kirilova, D. (2019) Importance of the Multimedia Presentations for the Recovery of Environmental Knowledge and Skills in Technology Training and Entrepreneurship. SocioBrains International. Scientific refereed online journal. No. 59, July 2019 ISSN 2367-5721, www.Sociobrains.com

Lazarova, S. (2016) Typical Mistakes of Students in the Preparation and Use of Presentations in Training in Environmental Studies, Man and Nature and Man and Society. Innovations in Education SU "Bishop Konstantin Preslavski", Shumen, 2016 | Faber Publishing House, 2016 | ISBN: 978-619-00-0477-6

McDonald, D. (2004) The Influence of Multimedia Training on Users' Attitudes: Lessons Learned. Computers \& Education 42 (2004) 195-214

https://www.cin.ufpe.br/ mlearning/intranet/Instructional\%20design/\%5BMcDonald\%5D $\% 20$ The $\% 20$ influence $\% 20 \mathrm{of} \% 20 \mathrm{~m}$ ultimedia\%20training\%20on\%20users\%20attitudes-\%20lessons\%20learned.pdf

Petrova, I., M. Petrova (2007) Development of the Elementary School Students' Motivation for Studying the Nature Using Multimedia. Pedagogical almanac. University of Veliko Tarnovo "St. St. Cyril and Methodius "- university publishing house. 2007, vol. 15, no. 1, pp. 230-234. https://journals.uni-vt.bg/almanac/bul/vol15/iss1/

Peycheva, Y. (2011) Multimediynata prezentatsiya v pomosht na tehnologichnoto planirane po Domachen bit $\mathrm{i}$ tehnika \{ The Multimedia Presentation in Support of the Technological Planning of Home Life and Equipment\}, Cfiiection 40 years of Chumen University, Shumen: UI „Ep. K. Preslavski”, 2011 t. 1. 5.

Peycheva, Y. (2018) Poznavatelna aktivnost I kreativnost v obuchenieto po tehnologii I predpriemachestvo \{Cognitive Activity and Creativity in Technology and Entrepreneurship Education\}. Shumen: UI „Ep. K. Preslavski”.

Ronsivalle G. B., M. Orlando (2011) Designing Multimedia Presentations in Classroom: An Operational Model for Teachers Conference. ACTC 2011 (Asian Conference on Technology) At: Osaka

https://www.researchgate.net/publication/259866412_Designing_Multimedia_Presentations_in_Classroom_An_Operational_ Model_for_Teachers

Trifonova, M. (2018) Competences for Creating Learning Resources in a Digital Environment. In: Yearbook of the Pedagogical Faculty of TrU - St. Zagora, 15, 136-154.

Trifonova, M. (2018) Digital-Pedagogical Competencies. In: Science and Technologies, Vol. VIII, 2018 http://www.sustz.com/journal/7/1767.pdf 